Published in final edited form as:

Int J Obes (Lond). 2012 September ; 36(9): 1165-1169. doi:10.1038/ijo.2011.266.

\title{
Physical Activity and Weight Gain Prevention in Older Men
}

Eric J Shiroma, MEd, MSc ${ }^{1,2}$, Howard D Sesso, ScD ${ }^{1,2,3}$, and I-Min Lee, MBBS, ScD ${ }^{1,2}$

${ }^{1}$ Department of Epidemiology, Harvard School of Public Health, Boston, MA

2Division of Preventive Medicine, Brigham and Women's Hospital, Harvard Medical School, Boston, MA

${ }^{3}$ Division of Aging, Brigham and Women's Hospital, Harvard Medical School, Boston, MA

\begin{abstract}
Background-Physical activity and adiposity are important predictors of mortality, even in older individuals. However, it is unclear how much physical activity is needed to prevent weight gain in older persons.
\end{abstract}

Purpose-To examine the associations of different amounts of physical activity with weight gain prevention in older men.

Methods-5,973 healthy men (mean age, 65.0 y) from the Harvard Alumni Health Study were followed from 1988 to 1998. At baseline (1988), in 1993, and 1998, men reported their recreational physical activity and body weight. Physical activity was categorized as: < 7.5 MET-hr/ week (7.5 MET-hr/week corresponds to the minimum required by the 2008 US federal guidelines), 7.5 to <21 MET-hr/week (21 MET-hr/week corresponds to the 2002 Institute of Medicine $[\mathrm{IOM}]$ guideline), and $\geq 21 \mathrm{MET}$-hr/week. Meaningful weight gain was defined as an increase of $\geq 3 \%$ of body weight.

Results-Overall, weight tended to be stable over any 5-year period; mean change, -0.08 $(\mathrm{SD}=4.44) \mathrm{kg}$. However, $21 \%$ of men experienced meaningful weight gain over any 5-year period. In multivariate analyses, compared to men expending $\geq 21 \mathrm{MET}-\mathrm{hr} / \mathrm{week}$, those expending 7.5 to <21 MET-hr/week had an odds ratio (OR) of 1.35 (95\% confidence interval: 1.03, 1.77) for meaningful weight gain, and men expending <7.5 MET-hr/week, an OR of $1.16(1.01,1.33)(\mathrm{p}$, trend $=0.09$ ).

\footnotetext{
Users may view, print, copy, download and text and data- mine the content in such documents, for the purposes of academic research, subject always to the full Conditions of use: http://www.nature.com/authors/editorial_policies/license.html\#terms

Correspondence to: Eric Shiroma. Harvard School of Public Health. 677 Huntington Ave, Boston, MA 02115. eshiroma@hsph.harvard.edu.

Publisher's Disclaimer: The manuscript has not been published nor is it under consideration for publication elsewhere, and will not be published elsewhere while under consideration by Int J Obesity. All authors have made substantive contributions to the study and will sign a statement attesting authorships, disclosing all potential conflicts of interest, and releasing copyright should the manuscript be acceptable for publication.

Conflict of Interest

Drs Lee, Sesso, and Mr Shiroma's work have been funded by the NIH. Dr Lee has served as a consultant to Virgin HealthMiles. Dr. Sesso and Mr. Shiroma have no commercial associations or sources of support that might post a conflict of interest.
} 
Conclusions-Among older men, those with lesser levels of physical activity were more likely to gain weight than men satisfying the 2002 IOM guidelines of $\geq 21 \mathrm{MET}-\mathrm{hr} /$ week ( 60 minutes per day of moderate-intensity physical activity).

\section{Keywords}

epidemiology; exercise; older men; weight gain

\section{Introduction}

Adiposity remains a significant public health problem; in 2008, $68 \%$ of adults in the US were overweight (body mass index (BMI) $\geq 25 \mathrm{~kg} / \mathrm{m}^{2}$ ) or obese (BMI $\geq 30 \mathrm{~kg} / \mathrm{m}^{2}$ ). Its prevalence increases with age, as $78 \%$ of men and $69 \%$ of women over the age of 60 years are overweight or obese.(ref. 1) This is of concern because adiposity is associated with higher mortality rates, including in older individuals.(ref. 2) Studies have demonstrated the beneficial health effects of reducing excessive body weight by dietary and physical activity interventions, pharmacotherapy, and bariatric surgery.(ref. 3, 4, 5, 6, 7) Particularly with lifestyle interventions and pharmacotherapy, many individuals do not maintain the weight lost.(ref. 8) Thus, focusing on the prevention of weight gain may be a more proactive approach than focusing solely on losing weight and maintaining that loss. However, few data are available regarding the prevention of weight gain, compared to data on reducing weight.(ref. 9)

Physical activity is an important part of weight management.(ref. 5, 10, 11) In 2008, the federal government recommended at least 150 minutes of moderate-intensity physical activity a week for health benefits.(ref. 12) While this level of physical activity clearly is associated with reduced risks of premature mortality and chronic diseases, it is less certain whether it is sufficient to prevent weight gain.(ref. 13,14) Thus, this study aims to examine the associations of different amounts of physical activity, defined using prevailing guidelines, with the prevention of subsequent weight gain in older men over a period of 10 years.

\section{Methods}

\section{Study Participants}

Subjects were from the Harvard Alumni Health Study, an ongoing prospective cohort study of men matriculating at Harvard University between 1916 and 1950.(ref. 15) Beginning in 1962, men completed health questionnaires periodically that queried subjects on sociodemographic characteristics, health habits, and personal and family medical history. For the present study 12,805 men who returned a health questionnaire in 1988 were eligible. We then applied the following exclusion criteria: we excluded 611 men with missing information on physical activity, weight, or height in 1988, leaving 12,194 men. We further excluded 5,258 men who developed cardiovascular disease (CVD) or cancer prior to the end of follow-up for this study in 1998 to minimize bias from changes in physical activity or weight resulting from poor health. Of the remaining 6,936 eligible men, 5,973 men (86.1\%) 
provided follow-up weight in 1993 and/or 1998 and comprised the baseline population for this study.

\section{Assessment of Physical Activity}

In 1988 and 1993, men reported the number of flights of stairs climbed, blocks walked, and frequency and duration spent in sports/recreational activities. By summing the average energy expenditure for each of these activities in metabolic-equivalent (MET) hours per week(ref. 16), we estimated the total energy expended. This physical activity questionnaire has been extensively tested for reliability and validity, including against doubly labeled water (Spearman $\mathrm{r}=0.67$ for recreational activities),(ref. 15) and test-retest correlations of 0.7-0.8 have been obtained over 4 weeks.(ref. 17, 18)

We classified men into 3 categories of physical activity, <7.5, 7.5 to $<21$, and $\geq 21$ MET-hr/ week, based on the most current 2008 US federal physical activity guidelines $(150 \mathrm{~min} /$ week of moderate-intensity activity, equivalent to 7.5 MET-hr/week(ref. 12)) —and the amount recommended by a 2002 Institute of Medicine [IOM] report which specifically focused on weight control and obesity prevention (60 min/day of moderate-intensity activity, or 21 MET-hr/week)(ref. 19), although the basis for this amount has been questioned.(ref. 13)

\section{Assessment of Weight and Other Variables}

Weight was self-reported at baseline in 1988, and again in 1993 and 1998. We defined meaningful weight gain to be an increase of $23 \%$ of body weight(ref. 20) assessed over any 5-year period (1988 to 1993, or 1993 to 1998).

In 1988, we also collected information on age, height (to calculate body mass index (BMI), in $\mathrm{kg} / \mathrm{m}^{2}$ ), diet (using a 23-item semi-quantitative food frequency questionnaire), smoking habits, and physician-diagnosed diabetes, hypertension, and high cholesterol. Information on all variables except diet was updated in 1993.

\section{Statistical Analysis}

We compared baseline characteristics of men across the three categories of physical activity. We then examined prospective changes in weight, according to physical activity category, updated over time, using repeated measures linear regression to account for the correlation of within-person repeated observations. We next examined the odds ratios (OR) of meaningful weight gain associated with the 3 categories of physical activity on weight gain, also using repeated measures logistic regression. Three nested models were used: Model 1 adjusted for age, height, and baseline weight (all continuous variables); Model 2 further adjusted for smoking status (never, former, or current), alcohol consumption (never, 1 to 3 times per week, 4 to 6 times per week, or daily), vegetable intake $<1,1$ to 2 , or $\geq 3$ servings per day), fruit intake ( $<1,1$ to 2 , or 33 servings per day), saturated fat intake (quartiles), total caloric intake (quartiles); and Model 3 additionally included diabetes, hypertension, and high cholesterol (all no or yes).

We then investigated whether the associations of physical activity with meaningful weight gain differed by age, BMI, and smoking, using Model 2 for these analyses and testing for 
interactions using categorical variables. Age categories were selected to ensure a reasonable number of men in each group, and BMI categories were based on standard cutpoints.(ref. 21) While we tried to minimize bias from changes in physical activity and weight due to ill health by excluding men with CVD and cancer, there may have remained men with other illnesses. Thus, we conducted sensitivity analyses by including only men who did not lose $>5 \%$ of body weight over any 5 year period $(n=5,287)$. We also repeated analyses using an alternate definition of meaningful weight gain, $\geq 2.3 \mathrm{~kg}(5 \mathrm{lb})$.(ref. 5) Statistical analyses were conducted using SAS version 9.2 (SAS Institute Inc, Cary, North Carolina).

\section{Results}

At baseline, $24.5 \%$ of the men expended <7.5 MET-hr/week in physical activity, 27.5\% expended 7.5 to $<21$ MET-hr/week, and 48.0\% expended $\geq 21$ MET-hr/week. The mean age at baseline was 65.0 years. Age, height, total caloric intake, and history of hypertension were similar across baseline physical activity levels (Table 1). Weight, BMI, current smoking, history of diabetes, and history of hypertension were inversely related to physical activity level, while alcohol, vegetable, and fruit consumption increased with activity level. Total caloric intake was similar across activity levels, but less active men expending <7.5 MET$\mathrm{hr} /$ week consumed more saturated fat than more active men.

Among all men, weight tended to be stable over each 5-year period, with a mean change of $-0.08(\mathrm{SD}=4.44) \mathrm{kg}$. However, $21.1 \%$ of men ( $\mathrm{n}=1167$ of 5,527 men) had meaningful weight gain ( $33 \%$ body weight) between 1988 and 1993, as did 20.6\% ( $n=721$ of 3,508 men) between 1993 and 1998. We prospectively examined weight gain over time by physical activity level, allowing physical activity to be updated over time (Table 2). Compared to men expending $221 \mathrm{MET}$-hr/week, men expending 7.5 to $<21 \mathrm{MET}$-hr/week gained 0.04 ( $\mathrm{SD}=0.11) \mathrm{kg}$ ( $\mathrm{p}=0.71$ ), adjusting for age, height, baseline weight, smoking status, alcohol consumption, and the intake of vegetables, fruit, saturated fat, and total calories. For men expending <7.5 MET-hr/week, the men lost $0.18(\mathrm{SD}=0.14) \mathrm{kg}(\mathrm{p}=0.21)$. Adding physician-diagnosed diabetes, hypertension, and high cholesterol to the analytic model resulted in very similar findings. The association of physical activity with weight gain did not differ by age ( $\mathrm{p}$, interaction=0.42), BMI ( $\mathrm{p}$, interaction=0.62), or smoking status ( $\mathrm{p}$, interaction $=0.49$ ).

Table 3 shows the odds of meaningful weight gain ( $23 \%$ of body weight) over any 5 years according to time-varying physical activity level. In multivariate analyses that controlled for height, baseline weight, age, smoking status, alcohol consumption, and the intake of vegetables, fruit, saturated fat, and total calories, compared to men expending $\geq 21 \mathrm{MET}$ hours week, men expending 7.5 to <21 MET-hr/week had an odds ratio (OR) of 1.35 (95\% confidence interval: $1.03,1.77$ ) for meaningful weight gain, and men expending <7.5 MET$\mathrm{hr} /$ week had an OR of $1.16(1.01,1.33)(\mathrm{p}$, trend $=0.09)$. Although the relation appeared to be U-shaped, there was no significant difference in the odds of meaningful weight gain comparing men in the two lowest activity categories $(\mathrm{p}=0.34)$.

While no statistically significant interaction by BMI was observed ( $\mathrm{p}$, interaction=0.69), there appeared to be a stronger association between physical activity and meaningful weight 
gain in men with BMI $<25 \mathrm{~kg} / \mathrm{m}^{2}$ : corresponding ORs were $1.56(1.07,2.25)$ for men expending 7.5 to <21 MET-hr/week and $1.20(1.04,1.50)$ for men expending < $7.5 \mathrm{MET}-\mathrm{hr} /$ week, respectively (p, trend=0.06). The ORs were $1.11(0.72,1.71)$ and $1.05(0.85,1.31)$ for overweight men ( $\mathrm{p}$, trend $=0.90)$, and $1.45(0.38,5.48)$ and $1.20(0.62,2.34)$ for obese men $(\mathrm{p}$, trend $=0.86$ ). The association of physical activity with meaningful weight gain did not differ by age $(p$, interaction $=0.34$ ) or smoking status ( $p$, interaction $=0.43)$. Using the alternate definition of meaningful weight gain ( $\geq 2.3 \mathrm{~kg}$ ), (ref. 5) similar results were observed (data not shown).

In sensitivity analyses, limited to men who did not lose $>5 \%$ of body weight during any 5 years in order to minimize bias from ill health, the association between lower physical activity levels and increased odds of meaningful weight gain was stronger, compared with the whole study population. Compared to men expending $\geq 21$ MET-hr/week, men expending 7.5 to <21 MET-hr/week had an OR of $1.51(1.13,2.07)$ for meaningful weight gain, and men expending <7.5 MET-hr/week, an OR of $1.23(1.06,1.42)(\mathrm{p}$, trend=0.02). As before, no significant differences by age ( $\mathrm{p}$, interaction=0.37), BMI (p, interaction=0.36), or smoking status $(\mathrm{p}$, interaction $=0.44)$ were observed.

2,259 men (37.8\%) were identified as successfully having maintained normal weight; defined as men possessing a normal BMI $\left(<25.0 \mathrm{~kg} / \mathrm{m}^{2}\right)$ at baseline (1988), 1993, and 1998; and who gained $<3 \%$ of body weight over any 5 -year period. Their median activity levels were 22.2 and 32.7 MET-hr/week respectively in 1988 and 1993, with an overall median level of 25.3 MET-hr/week during the entire follow-up period, equivalent to approximately 70 minutes a day of moderate-intensity physical activity.

\section{Comment}

In this cohort of older men, average weight remained stable over 10 years of follow-up; however, about one-fifth of men gained a meaningful amount of body weight ( $>3 \%$ )(ref. 20) over any 5 year period. Meaningful weight gain was inversely related to physical activity level, as men with lower levels of physical activity were more likely to gain $33 \%$ of body weight over any 5 year period than men satisfying the 2002 IOM guideline of $\geq 21 \mathrm{MET}-\mathrm{hr} /$ week (approximately 60 minutes per day of moderate-intensity physical activity). In addition, normal weight men who successfully maintained normal weight with no meaningful weight gain over the ten years of follow-up expended a median of 25.3 MET-hr/ week, or approximately 70 minutes a day of moderate-intensity physical activity. This amount exceeds the minimum recommended by the 2008 federal guidelines, which focus on overall health, but is more in line with the IOM guideline for preventing weight gain.(ref. 19)

These findings suggest that physical activity has a modest but potentially important role in weight control among older men.(ref. 5, 10, 20) While there is a large body of literature on weight loss among those already overweight and obese, few studies have quantified how much physical activity is needed to maintain healthy weight over the long term.(ref. 5, 20, 22, 23, 24) The Physical Activity Guidelines Advisory Committee report, which provided the scientific basis for the 2008 federal physical activity guidelines, noted that while clear 
evidence of a dose-response relationship between physical activity and weight loss is present, data on long-term weight stability is sparse.(ref. 24) Existing data on weight stability come primarily from short-term clinical trials in which weight was not the primary outcome. In such studies, 13 to $26 \mathrm{MET}$-hr/week were needed for weight maintenance over 8 to 16 months.(ref. 24) Our data are congruent with higher end of this range for 10-year weight maintenance.

The present findings are similar to those among middle-aged and older women of the Women's Health Study (mean age, 54 years), in which women who maintained their weight over 13 years of follow-up participated in an average of 60 minutes per day of moderateintensity physical activity.(ref. 5) Previous studies in younger individuals have also emphasized how high levels of physical activity may blunt weight gain. In the CARDIA study, 18 to 30 year old men who maintained higher physical activity levels ( 2608 exercise units, with 300 exercise units equated to approximately 150 minutes per week of moderateintensity activity) gained 2.6 fewer kg per year over 20 years compared to men with lower activity ( $<340$ exercise units), while women maintaining higher activity levels ( 2398 exercise units) gained $6.1 \mathrm{~kg}$ less per year over the same period compared to women with lower activity ( $<192$ exercise units).(ref. 22)

Ascertaining the amount of physical activity to prevent initial weight gain is important because once overweight, many people are unable to maintain non-surgical post-intervention weight loss(ref. 25) and remain overweight. In a study of 1869 overweight/obese AfricanAmerican and white men and women who had lost $25 \%$ of their weight, $66 \%$ subsequently did not sustain $75 \%$ of their weight loss over a five-year period.(ref. 26) In addition to increasing risks for chronic diseases, physical inactivity and obesity are associated with decreased physical function in older adults.(ref. 27, 28) In a recent 1-year clinical trial of 107 obese adults aged $\ 65$ years who were randomly assigned to a control group, a weightmanagement (diet) group, an exercise group, or a weight-management-plus-exercise (dietexercise) group, Villareal et al. showed that those assigned to a combination of diet and exercise had a greater increase in physical performance compared to diet or exercise alone; however, those assigned to exercise alone also improved their physical performance compared to the control group ( $\mathrm{p}<0.001$ for both comparisons).(ref. 28)

Strengths of the current study include a large number of older men with a decade of followup and multiple assessments of detailed physical activity and weight that allow for the quantification and translation to clinical and public health recommendations. Previous studies with less detailed physical activity assessments are unable to determine the specific amount associated with less weight gain. In addition, potentially important confounders such as smoking and diet were controlled for; and information on non-dietary confounders was updated over time.

The current study was limited by having a self-reported assessment of physical activity. However, the questionnaire used has been extensively tested for reliability and validity.(ref. $15,17,18)$ Studies using this questionnaire have produced the expected inverse associations of physical activity with mortality and cardiovascular disease.(ref. 29, 30) Weight was also self-reported, but self-reported body weight has been shown to be highly correlated with 
measured body weight in older men ( $\mathrm{r}=0.97)$.(ref. 31) In this study, diet was assessed with a brief 23-item questionnaire, and only at baseline, allowing for the possibility of residual confounding.

We were unable to differentiate between fat-free mass and fat mass for those who lost weight. Physical activity among older men may be attenuating the effects of both muscle loss and the prevention of fat mass gain. Villareal et al showed that older adults (65 years and older) randomly assigned to (increase?) exercise significantly decreased fat mass $(\mathrm{p}=0.004)$ and increased lean body mass $(\mathrm{p}<0.0001)$ compared to the control group.(ref. 28) Among older individuals, physical activity may not be as strongly related to weight loss because of gains in lean body mass. However, we did not observe an interaction with age in the current study. Additionally, illness may have resulted both in weight loss and declining physical activity, leading to a spurious relation between physical activity and weight loss. However, this is unlikely as we excluded men with major illnesses. In sensitivity analyses, when we excluded men who had lost more than $5 \%$ of their weight, our observed trends strengthened. We did not have information on diagnoses of injuries and arthritis, which may have limited activity levels. Finally, because subjects in the present study were primarily Caucasian, reflecting the racial composition of Harvard University alumni of that period, and of high educational and socioeconomic status, the generalizability of findings may be limited.

In conclusion, older men not satisfying the 2002 IOM guidelines of $\geq 21 \mathrm{MET}$-hr/week (approximately 60 minutes per day [420 minutes per week] of moderate-intensity physical activity) were more likely to gain weight over a decade of follow-up, compared with those who satisfied the 2002 IOM guidelines. Normal weight men who successfully maintained normal weight and who did not gain meaningful weight over the ten years of follow-up expended a median of 25.3 MET-hr/week, or approximately 70 minutes a day of moderateintensity physical activity. This exceeds the minimum recommended by the 2008 federal guidelines, which focus on overall health, but is in line with the IOM guidelines for preventing weight gain.(ref. 19) While important for weight control, these finding should not detract from the large body of literature clearly showing that 150 minutes of moderateintensity physical activity per week (e.g., , as recommended by the federal government for all biking, dancing, and swimming) adults including older adults aged $ð 65$ years, is sufficient to lower the risks of chronic diseases.(ref. 12)

\section{Acknowledgements}

We are grateful to Sarah E. Freeman and Alvin L. Wing for their help with the College Alumni Health Study. This study is supported by research grants DK081141 and CA130068 from the National Institutes of Health, Bethesda, MD.

This study is supported by research grants DK081141 and CA130068 from the National Institutes of Health, Bethesda, MD.

Dr Lee has served as a consultant to Virgin HealthMiles. Dr. Sesso and Mr. Shiroma have no commercial associations or sources of support that might pose a conflict of interest. 


\section{References}

1. Flegal KM, Carroll MD, Ogden CL, Curtin LR. Prevalence and trends in obesity among US adults, 1999-2008. JAMA. 2010; 303(3):235-41. [PubMed: 20071471]

2. Berrington de Gonzalez A, Hartge P, Cerhan JR, Flint AJ, Hannan L, MacInnis RJ, et al. Body-mass index and mortality among 1.46 million white adults. N. Engl. J. Med. 2010; 363(23):2211-9. [PubMed: 21121834]

3. Pontiroli AE, Morabito A. Long-term Prevention of Mortality in Morbid Obesity Through Bariatric Surgery. A Systematic Review and Meta-analysis of Trials Performed With Gastric Banding and Gastric Bypass. Ann. Surg. 2011

4. Nelson ME, Rejeski WJ, Blair SN, Duncan PW, Judge JO, King AC, et al. Physical activity and public health in older adults: recommendation from the American College of Sports Medicine and the American Heart Association. Med. Sci. Sports Exerc. 2007; 39(8):1435-45. [PubMed: 17762378]

5. Lee IM, Djousse L, Sesso HD, Wang L, Buring JE. Physical activity and weight gain prevention. JAMA. 2010; 303(12):1173-9. [PubMed: 20332403]

6. Shiroma EJ, Lee IM. Physical activity and cardiovascular health: lessons learned from epidemiological studies across age, gender, and race/ethnicity. Circulation. 2010; 122(7):743-52. [PubMed: 20713909]

7. Bales CW, Buhr G. Is obesity bad for older persons? A systematic review of the pros and cons of weight reduction in later life. J Am Med Dir Assoc. 2008; 9(5):302-12. [PubMed: 18519110]

8. Katan MB. Weight-loss diets for the prevention and treatment of obesity. N. Engl. J. 356 Med. 2009; 360(9):923-5.

9. Kumanyika SK, Obarzanek E, Stettler N, Bell R, Field AE, Fortmann SP, et al. Population-based prevention of obesity: the need for comprehensive promotion of healthful eating, physical activity, and energy balance: a scientific statement from American Heart Association Council on Epidemiology and Prevention, Interdisciplinary Committee for Prevention (formerly the expert panel on population and prevention science). Circulation. 2008; 118(4):428-64. [PubMed: 18591433]

10. Shaw K, Gennat H, O'Rourke P, Del Mar C. Exercise for overweight or obesity. Cochrane Database Syst. Rev. 2006; (4) CD003817.

11. Jakicic JM, Otto AD, Lang W, Semler L, Winters C, Polzien K, et al. The Effect of Physical Activity on 18-Month Weight Change in Overweight Adults. Obesity (Silver Spring). 2010

12. U.S. Department of Health and Human Services. Physical Activity Guidelines for Americans. 2008. In, 2008

13. Blair SN, LaMonte MJ, Nichaman MZ. The evolution of physical activity recommendations: how much is enough? Am. J. Clin. Nutr. 2004; 79(5):913S-920S. [PubMed: 15113739]

14. Wareham NJ, van Sluijs EM, Ekelund U. Physical activity and obesity 378 prevention: a review of the current evidence. Proc. Nutr. Soc. 2005; 64(2):229-47. [PubMed: 15960868]

15. Lee, I-M.; Paffenbarger, RS, Jr.. Design of present-day epidemiologic studies of physical activity and health. In: Lee, I-M., editor. Epidemiologic methods in physical studies. Oxford University Press; New York, NY: 2009. p. 100-23.

16. Ainsworth BE, Haskell WL, Whitt MC, Irwin ML, Swartz AM, Strath SJ, et al. Compendium of physical activities: an update of activity codes and MET intensities. Med. Sci. Sports Exerc. 2000; 32(9 Suppl):S498-504. [PubMed: 10993420]

17. Ainsworth BE, Leon AS, Richardson MT, Jacobs DR, Paffenbarger RS Jr. Accuracy of the College Alumnus Physical Activity Questionnaire. J. Clin. Epidemiol. 1993; 46(12):1403-11. [PubMed: 8263567]

18. Jacobs DR Jr. Ainsworth BE, Hartman TJ, Leon AS. A simultaneous evaluation of 10 commonly used physical activity questionnaires. Med. Sci. Sports Exerc. 1993; 25(1):81-91. [PubMed: 8423759]

19. Institute of Medicine. Dietary Reference Intakes for Energy, Carbohydrate, Fiber, Fat, Fatty Acids, Cholesterol, Protein, and Amino Acids (Macronutrients). Washington, DC: 2002. 
20. Jakicic JM. The effect of physical activity on body weight. Obesity (Silver Spring). 2009; 17(Suppl 3):S34-8. [PubMed: 19927144]

21. Physical status: the use and intrepretation of anthropometry. Report of a WHO Expert Committee. World Health Organization; Geneva: 1995.

22. Hankinson AL, Daviglus ML, Bouchard C, Carnethon M, Lewis CE, Schreiner PJ, et al. Maintaining a high physical activity level over 20 years and weight gain. JAMA. 2010; 304(23): 2603-10. [PubMed: 21156948]

23. Hankinson AL, Bouchard C, Liu K. Physical activity and weight gain over 20 years - reply. JAMA. 2010; 305(13):1297-1298.

24. Physical Activity Guidelines Committee. Physical Activity Guidelines Advisory Committee Report. Department of Health and Human Services; Washington, DC: 2008.

25. Katan MB. Weight-loss diets for the prevention and treatment of obesity. New England Journal of Medicine. 2009; 360(9):923-5. [PubMed: 19246365]

26. Phelan S, Wing RR, Loria CM, Kim Y, Lewis CE. Prevalence and predictors of weight loss maintenance in a biracial cohort: results from the coronary artery risk development in young adults study. Am. J. Prev. Med. 2010; 39(6):546-54. [PubMed: 21084075]

27. Riebe D, Blissmer BJ, Greaney ML, Garber CE, Lees FD, Clark PG. The relationship between obesity, physical activity, and physical function in older adults. J. Aging Health. 2009; 21(8): 1159-78. [PubMed: 19897781]

28. Villareal DT, Chode S, Parimi N, Sinacore DR, Hilton T, Armamento-Villareal R, et al. Weight loss, exercise, or both and physical function in obese older adults. N. Engl. J. ed. 2011; 364(13): 1218-29.

29. Lee IM, Sesso HD, Paffenbarger RS Jr. Physical activity and coronary heart disease risk in men: does the duration of exercise episodes predict risk? Circulation. 2000; 102(9):981-6. [PubMed: 10961961]

30. Sesso HD, Paffenbarger RS Jr. Lee IM. Physical activity and coronary heart disease in men: The Harvard Alumni Health Study. Circulation. 2000; 102(9):975-80. [PubMed: 10961960]

31. Fillenbaum GG, Kuchibhatla MN, Whitson HE, Batch BC, Svetkey LP, Pieper CF, et al. Accuracy of self-reported height and weight in a community-based sample of older African Americans and whites. J. Gerontol. A. Biol. Sci. Med. Sci. 2010; 65(10):1123-9. [PubMed: 20530243] 
Table 1

Baseline Characteristics of Men, by Physical Activity Level, Harvard Alumni Health Study ${ }^{a}$

\begin{tabular}{|c|c|c|c|}
\hline \multirow[b]{2}{*}{ Characteristic } & \multicolumn{3}{|c|}{ Physical Activity, MET-hr/week $b$} \\
\hline & $\begin{aligned} & <7.5 \\
(\mathrm{n} & =\mathbf{1 4 6 4})\end{aligned}$ & $\begin{array}{l}7.5 \text { to }<21 \\
(\mathrm{n}=1643)\end{array}$ & $\begin{array}{c}\geq 21 \\
(\mathrm{n}=2866)\end{array}$ \\
\hline Age, mean (SD), y & $65.8(7.5)$ & $64.6(6.8)$ & $64.9(6.8)$ \\
\hline Height, mean (SD), m & $1.79(0.07)$ & $1.79(0.06)$ & $1.80(0.07)$ \\
\hline Baseline weight, mean (SD), kg & $81.3(12.4)$ & $79.6(10.5)$ & $79.1(9.8)$ \\
\hline BMI, mean (SD), $\mathrm{kg} / \mathrm{m}^{2}$ & $25.4(3.5)$ & $24.8(2.8)$ & $24.5(2.6)$ \\
\hline $\begin{array}{l}\text { Energy expenditure, median (interquartile } \\
\text { range), MET-hr/week }\end{array}$ & $2.89(1.3-4.8)$ & $14.0(10.6-17.3)$ & $39.3(28.5-59.9)$ \\
\hline Current smokers $(\%)$ & $12.4 \%$ & $6.5 \%$ & $5.7 \%$ \\
\hline Consuming alcohol daily (\%) & $40.7 \%$ & $42.4 \%$ & $44.3 \%$ \\
\hline Total caloric intake, mean (SD), kcal/day & $1173(465)$ & $1177(464)$ & $1200(474)$ \\
\hline Highest quartile of saturated fat intake (\%) & $28.0 \%$ & $23.0 \%$ & $23.8 \%$ \\
\hline Consuming $\geq 3$ servings/day of vegetables ( $\%$ ) & $12.6 \%$ & $13.8 \%$ & $15.2 \%$ \\
\hline Consuming $\geq 3$ servings/day of fruit ( $\%)$ & $8.3 \%$ & $11.0 \%$ & $12.0 \%$ \\
\hline History of diabetes (\%) & $5.4 \%$ & $4.0 \%$ & $2.4 \%$ \\
\hline History of hypertension (\%) & $28.4 \%$ & $25.8 \%$ & $23.2 \%$ \\
\hline History of hypercholesterolemia (\%) & $18.5 \%$ & $20.2 \%$ & $19.1 \%$ \\
\hline
\end{tabular}

Abbreviations: BMI, body mass index, which is calculated as weight in kilograms divided by height in meters squared; MET, metabolic equivalent.

${ }^{a}$ Except for physical activity, weight, and BMI, data for other characteristics were not provided by all men.

${ }^{b}$ An expenditure of 7.5 MET-hr/week is equivalent to 150 minutes per week of moderate-intensity physical activity, the minimum recommended by the federal government; 21 MET-hr/week is equivalent to 60 minutes per day (420 minutes per week) of moderate-intensity physical activity, recommended by the Institute of Medicine. 


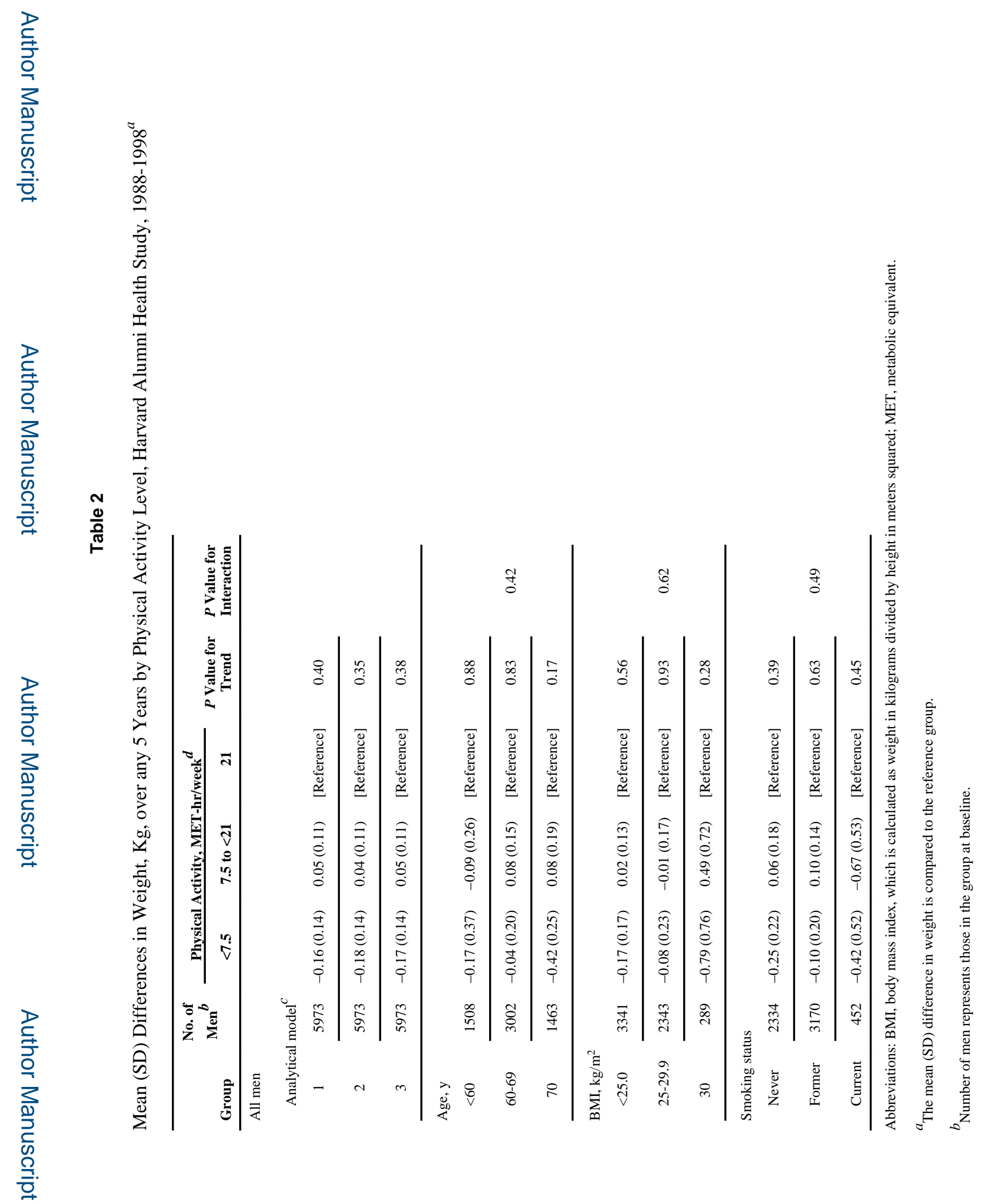




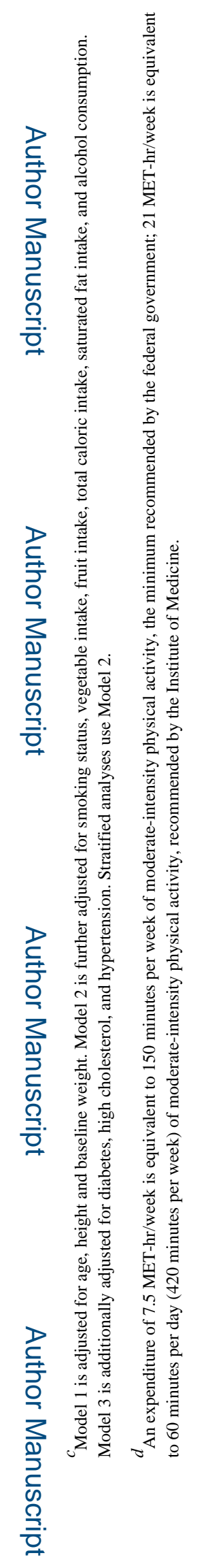




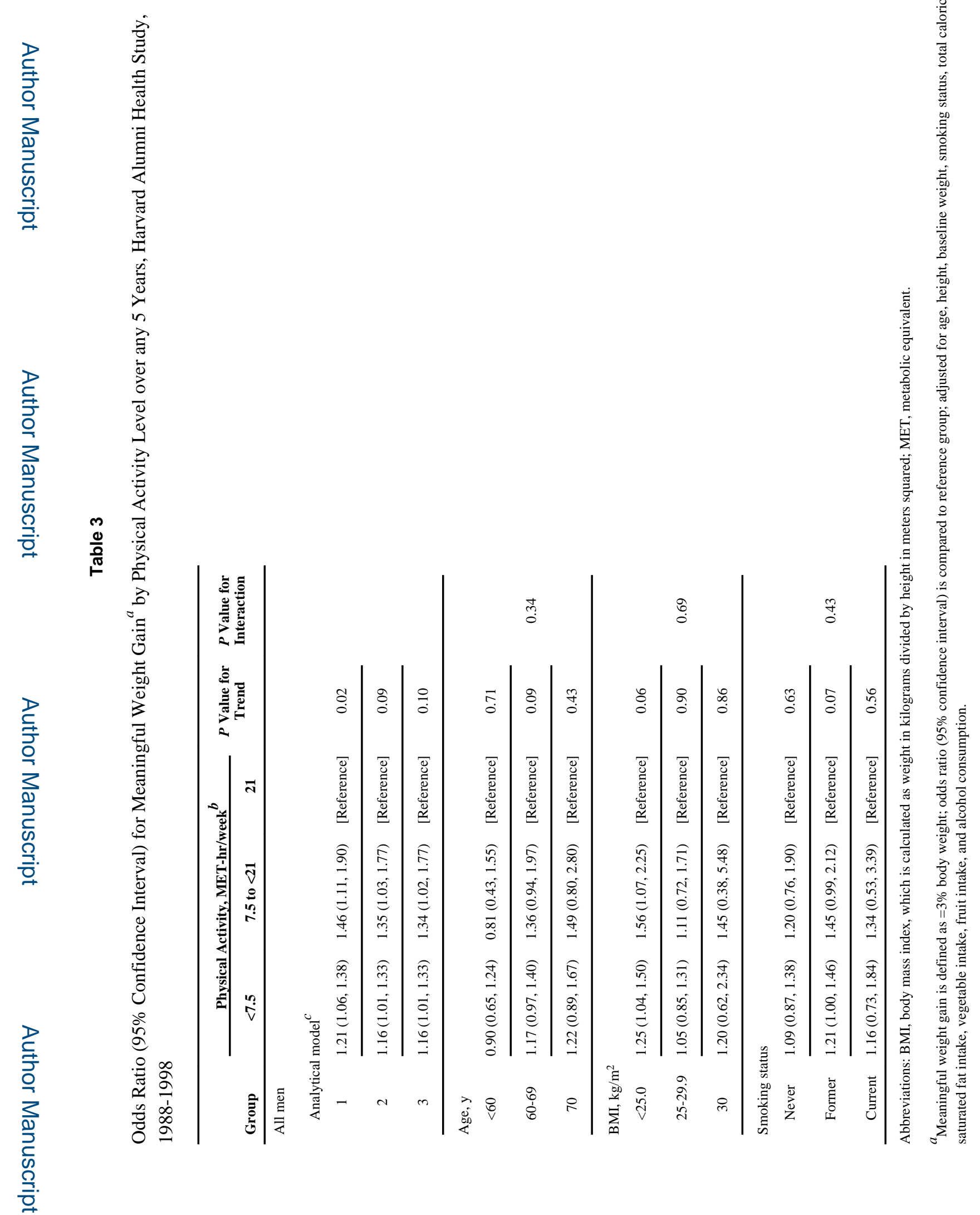




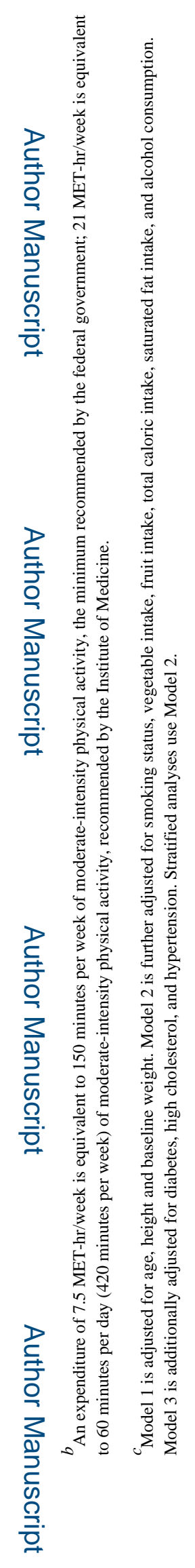

